\title{
La relevancia del microcrédito para las microempresas de Huaycán
}

\section{RESUMEN}

El presente ensayo analiza el creciente uso del microcrédito por parte de los microempresarios de la Comunidad Autogestionaria de Huaycán (Ate, Lima), donde ha habido una paulatina expansión de instituciones microfinancieras. El acceso a este crédito es clave para financiar la materia prima necesaria para su trabajo y ha sido incorporado en su imaginario como un medio clave para desarrollar su economía. Sin embargo, la acción del Estado todavía es limitada para promoverlo, dejando la iniciativa en el sector privado y negligiendo la responsabilidad de impulsar la inclusión económica de las microempresas y del llamado sector informal.

Palabras Clave: microempresa; microcrédito; política social; inclusión económica; economía informal; Huaycán.

\section{The relevance of micro-credit for micro-enterprises in Huaycan}

\section{ABSTRACT}

This paper analyzes the growing use of microcredit by microentrepreneurs in the Huaycán Community (Ate, Lima), where there has been a gradual expansion of microfinance institutions. Access to this credit is key to finance the raw materials needed for their work and has been incorporated into their imaginary as a key means to develop their economy. However, state action is still limited to promote it, leaving the initiative in the private sector and neglecting the responsibility to promote the economic inclusion of microenterprises and the so-called informal sector.

KEYwORDs: Microenterprise; microcredit; social policy; economic inclusion; informal economy; Huaycan. 
egún una encuesta aplicada recientemente a un grupo de microempresarios/as de Huaycán, puede señalarse que estos recurren regular y permanentemente a solicitar créditos tanto a las instituciones del sistema financiero como a familiares prestamistas. Huaycán, ubicado en la zona 6 del distrito de Ate, es un asentamiento que se ha desarrollado desde 1984 y que hoy en día tiene cerca de 150000 habitantes, una población sumamente heterogénea como resultado de procesos de migración, consolidación urbana precaria e importantes niveles de pobreza, sobre todo en las zonas altas de reciente invasión, pero también un importante desarrollo de microempresas e iniciativas económicas populares que permiten la generación de ingresos y empleo a la población.

El crédito es una necesidad para estos microempresarios en tanto requieren financiar su producción, y es un proceso recurrente. Estos empresarios buscan pedidos de diversos tipos: licitaciones, de colegios, servicios para construcciones, habilitación de casas u oficinas o de comerciantes mayoristas. El contar con un pedido garantiza, en cierta medida, la venta de la producción o servicio y minimiza el riesgo de tener que producir sin saber dónde va uno a colocar luego su producto, si es que no se tiene un canal de comercialización desarrollado.

Sin embargo, la producción del pedido obtenido requiere contar con el dinero necesario para cubrir los insumos y materiales e incluso pagar la mano de obra que intervendrá en la confección o habilitación, lo que puede implicar montos considerables para un microempresario dependiendo de la envergadura del pedido y generarle un problema de financiamiento al empresario. Usualmente los empresarios suelen solicitar al cliente un adelanto, que puede oscilar entre 30 a 50\%, y algunos empresarios — aunque son los menos- cuentan con cierto nivel de capital propio, pero estos dineros suelen quedar cortos para cubrir los gastos requeridos y se hace necesario recurrir a las fuentes de financiamiento accesibles.

Los empresarios de Huaycán han aprendido a manejar esta necesidad recurriendo a la creciente oferta de créditos a nivel local, especialmente a partir de la instalación en la zona de una gran diversidad de instituciones bancarias y microfinancieras, en los últimos diez años. El crédito de las instituciones financieras es hoy en día la principal fuente de financiamiento en número y monto para el $80 \%$ de los empresarios de Huaycán, que acuden de manera recurrente a este. Un 20\% acude a prestamistas o familiares, aunque el volumen de este crédito es menor.

Para un 64\% de los empresarios el acceso y manejo del crédito no representa un problema y lo han integrado a su dinámica de gestión. Un 36\% afronta problemas en el transcurso del proceso de devolución, sobre todo por dificultades al momento de vender o colocar su producción, pero un 11 a $20 \%$ de empresarias afronta problemas que los llevan u obligan a renunciar al crédito formal, afrontando perdidas en el negocio, ya que los intereses se vuelven sumamente onerosos ante la presencia de fallas o caídas en el negocio.

\section{La oferta de microcrédito en Huaycán}

Huaycán cuenta con un segmento de MYPEs que ha superado los estadios iniciales y que tienen cierto nivel de acumulación, ubicándose en un tramo de 13 a 18 UITs de ventas anuales, por encima del promedio limeño para las microempresas. Los empresarios y empresarias, han podido adaptarse a los cambios, manejando costos, mercados e incluso experimentando cierto nivel de colaboración entre ellos. Algunos de estos empresarios logran incrementar ventas buscando mercados más allá de lo local, como en Gamarra por ejemplo.

Los problemas más sentidos por los empresarios de Huaycán, según datos recogidos mediante diversas encuestas son: la falta de financiamiento $73 \%$, la falta de demanda para sus productos $45 \%$, la falta de maquinaria $45 \%$ y la escasez de mano de obra calificada $36 \%$.

Enfrentar la falta de financiamiento para los empresarios de Huaycán ha sido un proceso largo, en tanto las posibilidades de obtenerlo, en el mismo Huaycán, en su inicio eran limitadas. La oferta y las posibilidades de obtenerlo se han ido presentando en Huaycán en la medida de que se ha ido consolidando como ciudad con una dinámica poblacional y económica propia, lo que ha ido atrayendo a instituciones del sistema financiero.

Recién hacia mediados de los 90 empieza a presentarse oferta de microcréditos en la zona, primero por las ONG, más tarde por las Cajas Municipales, aunque esa oferta todavía era limitada frente al volumen de la actividad económica que empezaba a surgir; los microempresarios tenían en general que tramitar la posibilidad de acceder a un crédito en la zona central 
del distrito, en Vitarte, ante instituciones poco acostumbradas a responder a lógicas de la periferia. A partir de los ańos 2000 se incrementa la oferta financiera en Ate-Vitarte, pues se multiplican las agencias de las Edpymes, los bancos y las cajas municipales. «El crédito directo otorgado por la Banca Múltiple ha venido subiendo en el distrito de 48,397.00, miles de dólares en el 2003 a 500,753.00 en el 2007. Mientras que los depósitos totales, considerando los depósitos a la vista, de ahorro y a plazos en el 2003 hacían un total de 219,634 miles de dólares y en el 2007 ascendió a la suma de 428,459.65 dólares» (Palomares 2007: 77).

Huaycán, a pesar de su lejanía, empezó a ser mirada como una plaza con dinámica propia. Un primer grupo de instituciones financieras se instaló de manera gradual entre el 2003 al 2008 y varias más entre el 2011-2012. Hoy en día la presencia de las instituciones de microfinanzas en Huaycán es sumamente amplia, hay ya 12 instituciones entre bancos, financieras, cajas municipales, edpymes y ONG, además los promotores analistas de crédito de Compartamos y Qapaq recorren la zona y acaba de instalarse el Banco de la Nación en el local de la Municipalidad con miras a facilitar el pago de obligaciones con el Estado.

En general estas instituciones trabajan con el llamado crédito individual desde 500 soles, aunque suelen trabajar con préstamos promedio entre 3,000 a 5,000 soles con tasas de entre 30 y $60 \%$ anual pues cada cliente es evaluado según su riesgo e historial. Los prestamos suelen ser a un ańo plazo, aunque eventualmente se llega a plazos de dos y tres años, especialmente en caso de montos mayores, pudiendo llegar a 70 u 80 mil soles en el caso de las Cajas Municipales o Financieras y hasta 200 o 300 mil soles en el caso de los bancos, con tasas menores en este caso por ser créditos comerciales.

Los préstamos están orientados hacia capital de trabajo, aunque una parte de ellos va para pequeños activos fijos, como motos o máquinas, o para la habilitación de locales para negocio o producción. Los analistas de crédito son los calificadores del crédito, hacen el flujo de caja del negocio, analizan el historial y suelen pedir alguna garantía colateral, que puede o no ser formalizada legalmente: un aval, un local propio, mercadería, maquinas; aunque las instituciones financieras suelen insistir en que dan un préstamo sin garantías. La Edpyme Inversiones La Cruz pide garantías prendarias, en ese caso estamos cerca de un crédito pignoraticio. Los pagos de los prestamos suelen ser mensuales, iniciándose al mes de otorgado el crédito, no considerándose, al parecer, otro tipo de esquemas, que podrían favorecer al cliente. El Banco Azteca cobra el crédito de manera semanal y da facilidades para adelantar los pagos, aunque en alguna oportunidad el esquema de pago semanal ha sido denunciado por esconder altos intereses.

Estas instituciones entienden que están en un mercado con muchos ofertantes y que están compitiendo entre sí, tratan de fidelizar a sus clientes y asistirlos vía los analistas de crédito. Sin embargo, se aprecia algunos esquemas diferenciados, algunas instituciones, como Inversiones La Cruz o el Banco Azteca apuntan al muy pequeño microcrédito cercano al crédito de consumo; las financieras, MiBanco y Cajas Municipales apuntan si a microempresas que requieren créditos de manera sostenida, mientras que los bancos apuntan a clientes de envergadura. En la medida de que ahora existen holdings de bancos y micro financieras (BCP, MiBanco; BBVA con Financiera Confianza, Scotiabank con Crediscotia) les es posible trabajar con diversos segmentos de clientes, bancarizando a los que van subiendo de nivel.

Un esquema particular es el de la ONG Edaprospo Programa Prosperidad y el de la Financiera Confianza que prestan a grupos solidarios o bancos comunales, generalmente conformados por mujeres. En este caso estamos ante préstamos bastante pequeños, inferiores a 1000 soles donde se trabaja con ciclos de préstamos en el cual las beneficiarias aprenden a manejar el fondo, ahorrar y manejar montos mayores.

Algunas de estas instituciones tienen un portafolio de productos más amplios pues buscan atender a diversos segmentos. Crediscotia y Caja Huancayo por ejemplo buscan dirigirse también a trabajadores dependientes o crédito de consumo con miras a elevar su flujo de colocaciones. Ofrecen en ese sentido créditos, adelanto de haberes, tarjetas. Además con miras a captar fondos ofrecen ahorros, depósitos a plazos, cobro de servicios o de consumo de los supermercados.

Estas instituciones no cuentan con datos o estudios sobre el impacto del crédito en sus clientes, entienden que el crédito ayuda a los microempresarios sobre todo con la liquidez necesaria para sus negocios y son testigos de cómo varios de ellos han crecido, incrementando el negocio, viéndolos ampliar y remozar sus locales o adquiriendo vehículos. No hay un acompańamiento específico al desarrollo del microempresario. En todo caso se genera cierto nivel de interrelación entre 
el prestamista y el prestatario pues muchos de los clientes solicitan crédito de manera recurrente, dando 5 o 6 vueltas a lo largo de otros tantos años, aunque algunas instituciones acumulan 2 o 3 préstamos en la misma persona simultáneamente. Cabe señalar que las instituciones financieras son conscientes de que un segmento importante de sus clientes son compartidos con otras instituciones, señalan porcentajes de 40 a $60 \%$.

En el caso de los bancos comunales o grupos sociales el impacto estaría en lograr cierto nivel de empoderamiento y autonomía económica de las personas, mayoritariamente mujeres; en estricto no hay crecimiento pues el crédito es usado en pequeños negocios por campañas: productos de belleza, confecciones, limpieza. Pero los grupos aprenden a manejarse para ahorrar y prestar.

Los estimados realizados, en base a las declaraciones de los jefes de agencia de las instituciones financieras de Huaycán, permiten establece que el volumen de crédito anual asciende a un aproximado de 120 millones de soles con cerca de 25000 personas/créditos beneficiadas. Ese número supera en 5 veces la cantidad de microempresas estimadas en la zona, lo que puede deberse a que algunas instituciones prestan a empresarios de zonas colindantes (Horacio Zeballos, Pariachi, Naña), pero también al hecho de que se les presta a vendedores ambulantes y mototaxistas que no son usualmente contabilizados en el número de establecimientos. De todas maneras estamos hablando de un porcentaje de créditos, y hasta podríamos decir de inclusión financiera o bancarización, importante habida cuenta de que se estima en unas 80000 personas la población adulta de esta zona: $31 \%$, que se corresponde con el promedio nacional, cuando podría haberse supuesto que una zona marginal tendría un ratio menor.

\section{Los microempresarios de Huaycán frente al crédito}

Para conocer la actitud y conductas desarrolladas por los microempresarios frente al tema del financiamiento y microcrédio hemos realizado una encuesta con preguntas abiertas que nos permitiesen profundizar - a partir de la conversación que se generaba - en la forma como reaccionan frente a los desafíos o problemas que les van planteando la necesidad de financiar su actividad. Se aplicó la encuesta a 28 empresarios seleccionados en función de su experiencia y en base al conocimiento previo de su trabajo, básicamente carpinteros y/o confeccionistas por una cercanía personal con esos sectores, con miras a establecer pautas de comportamiento de los microempresarios/as frente al microcrédito.

El 61\% de ellos, 17 empresarios/as, pertenecen al sector de confecciones; el 29\%, 8 empresarios/as pertenecen al sector carpintería y un $11 \%, 3$ empresarios/ as pertenecen a otros sectores: artesanía, calzado y metal mecánica. Los/las confeccionistas cuentan con una producción muy variada tanto para el mercado local como para el de exportación (aunque ellos no exportan directamente), prendas de hombre o mujer: polos de vestir y deportivos, poleras, blusas, camisas, tops, bividís, vestidos, casacas, faldas, pantalones, shorts, legins así como buzos, uniformes, además de ropa militar y hospitalaria. Los/las carpinteros/as fabrican muebles de oficina: estantes, libreros y escritorios; muebles de hogar: roperos, dormitorios completos, reposteros, casillas de cocinas, closets, camas, puertas y ventanas, y mobiliario escolar (sillas, carpetas), además realizan servicios de acabado. Los otros productores fabrican monederos y cartucheras artesanales, calzados, góndolas y casilleros metálicos.

Estos empresarios/as, 18 hombres y 10 mujeres, el 64 y $36 \%$ respectivamente, contaban mayoritariamente con secundaria completa en un 60\%; un $29 \%$ contaba con algún nivel de educación superior y solo un 11\% tenían primaria o secundaria incompleta. La mayoría, un $68 \%$, cuenta con vivienda propia; el resto vive en vivienda alquilada; contar con vivienda propia es un activo muy importante al momento de solicitar un crédito. Las edades eran muy variadas, cubriendo un gran espectro, desde los 23 a 71 ańos. La cohorte más importante es la de 51 a 60 ańos con 9 casos, el 32\% de los encuestados.

TABLA 1

\begin{tabular}{|l|r|r|r|r|r|}
\hline $\begin{array}{c}\text { Rangos de } \\
\text { edad }\end{array}$ & Casos & Porcentaje & \multicolumn{2}{|c|}{$\begin{array}{c}\text { Años de operación de la } \\
\text { empresa }\end{array}$} \\
\hline De 23 a 30 & 6 & $21.43 \%$ & & & \\
\hline De 31 a 40 & 6 & $21.43 \%$ & De 3 a 5 & 3 & $10.71 \%$ \\
\hline De 41 a 50 & 5 & $17.86 \%$ & De 5 a 10 & 13 & $46.43 \%$ \\
\hline De 51 a 60 & 9 & $32.14 \%$ & De 10 a 20 & 5 & $17.86 \%$ \\
\hline De 61 a + (71) & 2 & $7.14 \%$ & De 20 a 27 & 7 & $25.00 \%$ \\
\hline Total & 28 & $100.00 \%$ & Total & 28 & $100.00 \%$ \\
\hline
\end{tabular}

Las personas encuestadas ya llevan, en general, varios años de operación como empresarios, el 89\%, 
25 casos, habían superado los 5 años de operaciones, lo que significa que estamos ante empresas con cierto nivel de consolidación y que han superado los primeros años. Un 43\%, 12 casos, de las empresas superaban los 10 años de funcionamiento, una de ellas llegaba a 27 años (ver gráfico 1). Los locales de sus talleres son propios en un $48 \%$ de los casos y miden, en promedio, 115 metros cuadrados; aunque el rango de tamaño es bastante amplio, desde 40 a $300 \mathrm{~m}^{2}$. La mayor parte, el $62 \%$, cuenta con 100 o menos metros cuadrados.

\section{GRÁFICO 1}

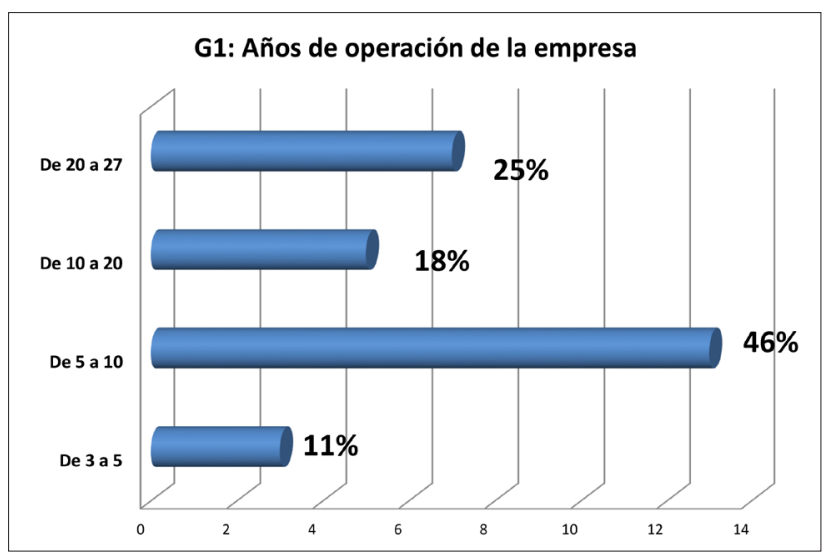

Básicamente son empresas familiares, pero cuentan ya con trabajadores asalariados, seguramente en la informalidad laboral. En promedio cuentan con 5 trabajadores, de hecho en 16 casos, el 57\% de los mismos, emplean de 4 a 5 trabajadores; un 25\%, 7 casos, muestran contar con un número significativo de trabajadores, 6 a 7 trabajadores, lo que es alto para una microempresa, ya que el promedio en Lima no llega a 2 trabajadores (ver gráfico 2).

\section{GRÁFICO 2}

\section{G2: Número de trabajadores por empresa}

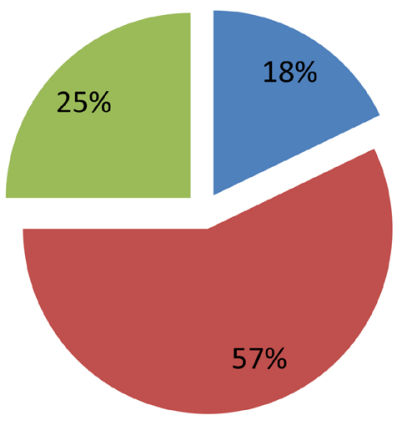

De 2 a 3

De 4 a 5

De 6 a 7

Promedio: 5 trabajadores por empresa
En estas empresas participan también los familiares del conductor o conductora, en un promedio de 2 TFNR por empresa; aunque en 8 casos, $28.57 \%$, el número de trabajadores familiares no remunerados oscila entre 3 a 5, 2 empresas no cuentan con este tipo de trabajadores.

\section{TABLA 2}

\begin{tabular}{|l|r|r|r|r|r|}
\hline \multicolumn{2}{|c|}{ Número de trabajadores } & \multicolumn{3}{|c|}{$\begin{array}{c}\text { Participación de familiares en el } \\
\text { negocio }\end{array}$} \\
\cline { 4 - 6 } \multicolumn{2}{|c|}{} & Con 1 & 8 & $28.57 \%$ \\
\hline De 2 a 3 & 5 & $17.86 \%$ & Con 2 & 10 & $35.71 \%$ \\
\hline De 4 a 5 & 16 & $57.14 \%$ & Con 3 a 5 & 8 & $28.57 \%$ \\
\hline De 6 a 7 & 7 & $25.00 \%$ & Sin familiares & 2 & $7.14 \%$ \\
\hline Total & 28 & $100.00 \%$ & Total & 28 & $100.00 \%$ \\
\hline
\end{tabular}

Fuente. Encuesta aplicada, elaboración propia.

Los niveles de ventas son significativos, en comparación al promedio de microempresas limeñas que es de 3500 soles mensuales aproximadamente. El promedio del nivel de ventas en las empresas entrevistadas en Huaycán es de 14800 soles; aunque la mayor parte se encuentra en el rango de 5001 a 10000 soles al mes donde están 13 casos, el 48\% de los entrevistados. Huaycán se ha caracterizado, ya desde hace muchos ańos, en contar con microempresas de mayor capacidad y experiencia que otras zonas de Lima.

TABLA 3

\begin{tabular}{|l|r|r|}
\hline \multicolumn{2}{|l|}{ Niveles de ventas, en soles } & Porcentajes \\
\hline De 1 a 5,000 mensual & 1 & $3.70 \%$ \\
\hline De 5,001 a 10,000 mes & 13 & $48.15 \%$ \\
\hline De 10,001 a 20,000 mes & 9 & $33.33 \%$ \\
\hline De 35,000 a 60,000 mes & 4 & $14.81 \%$ \\
\hline Total & 27 & $100.00 \%$ \\
\hline
\end{tabular}

Fuente. Encuesta aplicada, elaboración propia.

Estamos pues ante empresas con buena capacidad de venta y un ingreso regular lo que es una fortaleza para calificar ante un crédito. La utilidad que declaran, que preferimos calificar como margen operativo destinado a cubrir gastos generales y remuneración del dueño, es de $20 \%$ en promedio. Estamos nuevamente ante un promedio no necesariamente representativo ya que el rango de «utilidad» va de 8 a $40 \%$, la mayor parte de los empresarios, 58\%, 15 casos, tienen una 
«utilidad» de 8 a 20\%. En términos de dinero esa utilidad o margen operativo oscila entre 900 a 8,000 soles; el sector mayoritario, el $59 \%$, cuenta con una «utilidad» que oscila entre 900 a 2,000 soles, lo que no deja mucho margen de acumulación; un 19\% muestra un margen de entre 4,001 a 8,000 soles que significa si una probabilidad de acumulación.

\section{TABLA 4}

\begin{tabular}{|l|r|r|l|r|r|}
\hline \multicolumn{2}{|l|}{ Ratio «Utilidad»/Ventas } & \multicolumn{2}{l|}{ Valor de la Utilidad } & \\
\hline De 8 a 20\% & 15 & $57.69 \%$ & De 900 a 2,000 soles & 16 & $59.26 \%$ \\
\hline De 21 a 30\% & 8 & $30.77 \%$ & De 2,001 a 4000 & 6 & $22.22 \%$ \\
\hline De 31 a 40\% & 3 & $11.54 \%$ & De 4,001 a 8,000 & 5 & $18.52 \%$ \\
\hline Total & 26 & $100.00 \%$ & Total & 27 & $100.00 \%$ \\
\hline
\end{tabular}

Fuente. Encuesta aplicada, elaboración propia.

Un tema que es necesario analizar antes de pasar a estudiar la dinámica del microcrédito entre estos empresarios es la estrategia de ventas que tienen estos empresarios y encontramos que el $82 \%$ de ellos, 25 casos, buscan pedidos o servicios, vía licitaciones con el Estado o vinculaciones a otras empresas. Ello es sumamente importante a ser considerado pues implica que la producción esta prevendida y que el ordenante está sumamente interesado en recibirla por corresponder a una necesidad o estrategia de venta; en estos casos es costumbre en el mercado de que el ordenante o solicitante de un adelanto, que suele oscilar entre el 30 a $50 \%$ del valor del pedido. Esa suma de adelanto es clave para financiar el inicio de la producción, con lo cual las necesidades de financiamiento disminuyen.

Se considera que esa estrategia de trabajo ha sido seleccionada por los empresarios justamente porque expone menos a las necesidades de financiamiento, además de que disminuye el riesgo de enfrentar un mercado adverso a sus productos. Ciertamente, esta estrategia atenúa, pero no hace desaparecer los problemas de financiamiento de la producción por el otro $50 \%$ que el empresario debe enfrentar con capital propio o con préstamos. En general los empresarios reconocen tener que obtener los dos recursos.

Existe también un $18 \%$ de empresarios, cinco casos, básicamente carpinteros (cuatro carpinteros y un confeccionista, entre los de mayor capacidad de ventas) que si dirigen su producción a mercado abierto vendiéndola en ferias y galerías especializadas, al contado o a consignación. Ellos sí se preocupan más del tema del financiamiento, pues careciendo de un capital propio significativo, deben recurrir a los préstamos para poder financiar la producción.

\section{GRÁFICO 3}

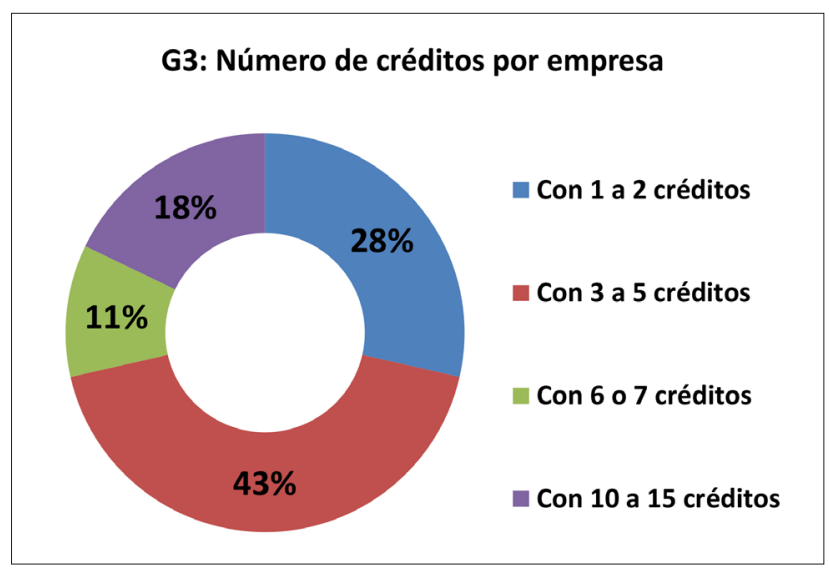

El $100 \%$ de estos empresarios ha recurrido - en un momento $u$ otro- a solicitar crédito, aunque la frecuencia con lo que lo han hecho es variable. Podemos decir que existe un grado de dependencia de los créditos diferente para cada caso. Tenemos un 29\% de empresas, 8 casos, que han solicitado 1 o 2 créditos a lo largo de su vida empresarial; tenemos un 53\% de empresas que han solicitado, y obtenido, entre 3 a 7 créditos, lo que nos indica ya un nivel de uso regular del crédito; y, por ultimo un 19\% de las empresas entrevistadas, 5 casos, que han obtenido entre 10 y 15 créditos y en los que podríamos decir que el crédito es la forma privilegiada de financiar su producción (ver gráfico 3).

TABLA 5

\begin{tabular}{|l|r|r|}
\hline Número de créditos & Casos & Porcentaje \\
\hline Con 1 a 2 créditos & 8 & $28.57 \%$ \\
\hline Con 3 a 5 créditos & 12 & $42.86 \%$ \\
\hline Con 6 0 7 créditos & 3 & $10.71 \%$ \\
\hline Con 10 a 15 créditos & 5 & $17.86 \%$ \\
\hline Total & 28 & $100.00 \%$ \\
\hline
\end{tabular}

Fuente. Encuesta aplicada, elaboración propia.

En la medida de que el número de créditos puede no ser un indicativo insuficiente, hemos construido un ratio de dependencia que relaciona número de créditos con el número de ańos de funcionamiento para establecer cuan significativo es el número de créditos recibidos tomando en cuenta la vida de la empresa. Un $32 \%$ de las empresas, 9 casos, tiene menos de $25 \%$ de 
dependencia, lo que significa que si bien ha adquirido créditos estos solo se solicitan de tiempo en tiempo; un $50 \%, 14$ casos, tienen grados de dependencia de 26 a $70 \%$, lo que nos indica que la solicitud de créditos, para esas empresas, ya empieza a ser algo cotidiano. En un $18 \%$ de los casos, 5 empresarios, tienen ratios que van desde 71 a 150\%; es decir, es decir que solicitan casi un crédito año y que en algunos casos más de uno al año (ver gráfico 4). La decisión de recurrir a un crédito para financiar su producción es algo normal y cotidiano en la vida de las microempresas de Huaycán; aun cuando hayan elegido estrategias de ventas que buscan minimizar esa necesidad.

TABLA 6. GRADO DE DEPENDENCIA FRENTE AL CRÉDITO. NÚMERO DE CRÉDITOS /NÚMERO DE AÑOS DE OPERACIÓN

\begin{tabular}{|l|c|c|}
\hline \multicolumn{1}{|c|}{ Ratios } & Casos & Porcentaje \\
\hline De 5 a 15\% & 3 & $10.71 \%$ \\
\hline De 16 a 25\% & 6 & $21.43 \%$ \\
\hline De 26 a 40\% & 7 & $25.00 \%$ \\
\hline De 41 a 70\% & 7 & $25.00 \%$ \\
\hline De 71 a 100\% & 3 & $10.71 \%$ \\
\hline De 101 a 150\% & 2 & $7.14 \%$ \\
\hline Total & 28 & $100.00 \%$ \\
\hline
\end{tabular}

Fuente. Encuesta aplicada, elaboración propia.

TABLA 7

ENTIDADES QUE HAN OTORGADO LOS CRÉDITOS VIGENTES

\begin{tabular}{|l|r|r|}
\hline Bancos & 7 & $20.59 \%$ \\
\hline Cajas & 4 & $11.76 \%$ \\
\hline Financieras & 6 & $17.65 \%$ \\
\hline MiBanco & 10 & $29.41 \%$ \\
\hline Familiares & 6 & $17.65 \%$ \\
\hline Prestamistas & 1 & $2.94 \%$ \\
\hline Total $^{\star}$ & 34 & $100.00 \%$ \\
\hline
\end{tabular}

Fuente. Encuesta aplicada, elaboración propia.

* El total de créditos supera al número de empresarios pues los empresarios nos han señalado las entidades con las que suelen trabajar. Algunos suelen solicitar y obtener préstamos en 20 más entidades.

Estos microempresarios recurren, actualmente, a solicitar y obtener sus créditos de las entidades bancarias, en un 50\%, 17 casos, incluyendo a MiBanco; ello nos señala la capacidad que ha tenido la banca comercial de posesionarse en este segmento los últimos años. Le siguen en importancia las financieras, los familiares, las Cajas Municipales y los prestamistas.
Aunque cabe señalar que algunos de, si no la mayoría, de los familiares, actúan como prestamistas pues suelen prestar con intereses, siendo estos más altos que los del sistema financiero en la zona (ver gráfico 5).

No hemos preguntado por las entidades que les habían concedido los créditos previos, pero percibimos que en los últimos ańos hay predilección por trabajar con la entidad en la cual están actualmente, de la cual se consideran clientes, señalando que cuentan con líneas de crédito.

\section{GRÁFICO 4}

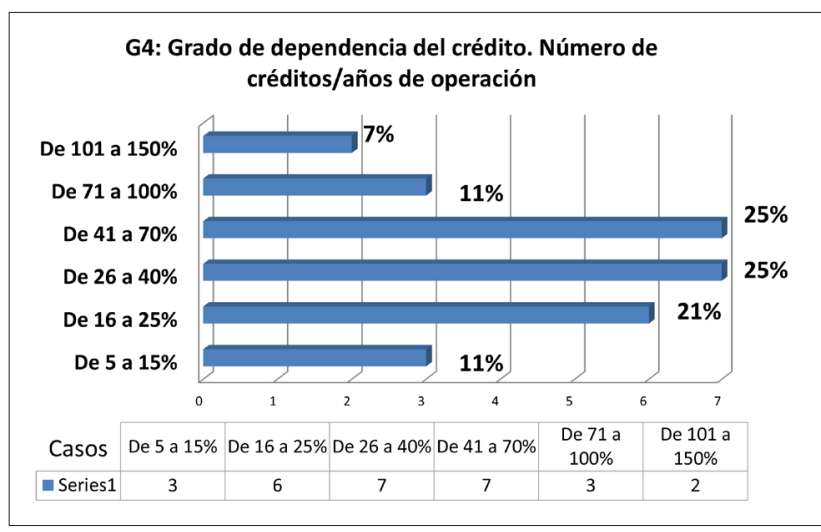

\section{GRÁFICO 5}

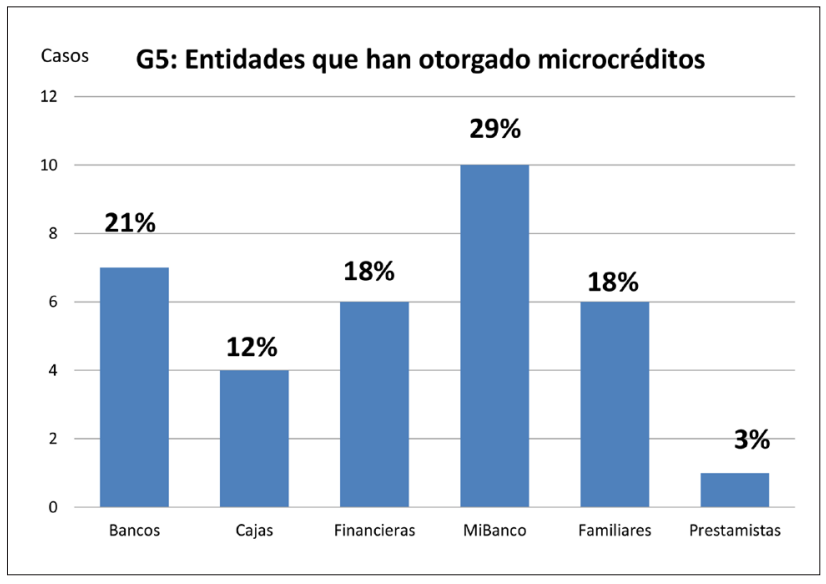

TABLA 8

\begin{tabular}{|l|r|r|l|r|r|}
\hline \multicolumn{2}{|l|}{ Monto del préstamo en soles } & \multicolumn{2}{l|}{ Periodo del préstamo } & \multicolumn{2}{l|}{$\%$} \\
\hline De 1,000 a 2,000 & 7 & $25.00 \%$ & Menos de 6 meses & 7 & $25.00 \%$ \\
\hline De 5,000 a 10,000 & 6 & $21.43 \%$ & 1 año & 13 & $46.43 \%$ \\
\hline De 10,001 a 20,000 & 9 & $32.14 \%$ & Año y medio & 2 & $7.14 \%$ \\
\hline De 20,001 a 40,000 & 4 & $14.29 \%$ & 2 años & 6 & $21.43 \%$ \\
\hline De 50,000 o más & 2 & $7.14 \%$ & Total & 28 & $100.00 \%$ \\
\hline Total & 28 & $100.00 \%$ & & & \\
\hline
\end{tabular}

Fuente. Encuesta aplicada, elaboración propia. 


\section{GRÁFICO 6}

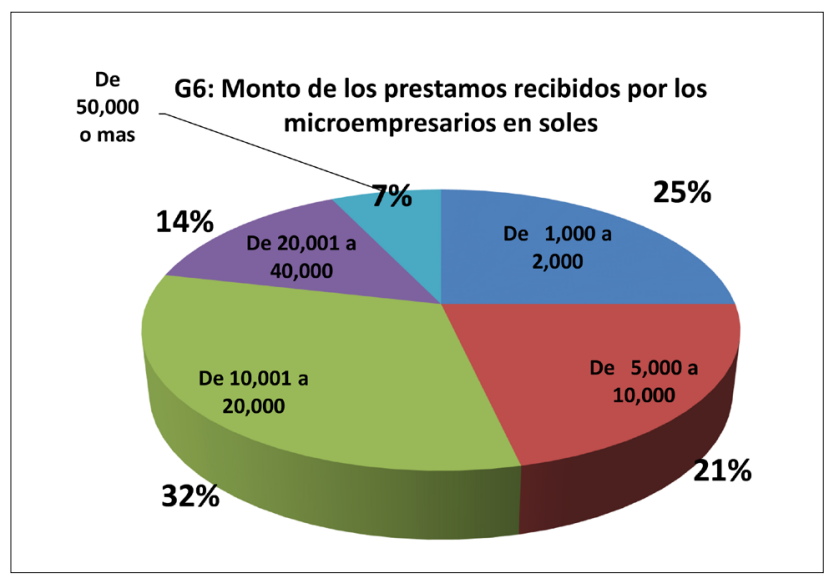

El monto de los préstamos obtenidos, es variable, va desde los 1000 a los 70000 soles, con un promedio de 17200 soles. El 46\% de los casos, 13 empresarios/ as, corresponde a préstamos de menos de 10000 soles; mientras que otro $46 \%$ ha solicitado créditos que oscilan entre 10001 y 40000 soles, estamos hablando ya de montos importantes. En 2 de los casos los montos obtenidos superan los 50000 soles. Los montos más pequeños corresponden, en general, a los montos solicitados a los familiares (ver gráfico 6). Los plazos de los prestamos suelen ser de un año, 46\%; aunque pueden llegar hasta dos años, obviamente para los montos más importantes. Los plazos cortos, de menos de 6 meses, corresponden usualmente a los prestamistas familiares.

Las tasas a los cuales suelen obtenerse estos préstamos oscilan entre 2 y $3 \%$ mensuales, con una tendencia hacia el $2 \%$ lo que significa que hay un descenso significativo de la tasa de interés en el sistema, o al menos de que los empresarios lo perciben así. No hemos podido constatar la existencia o no de otros costos adicionales que eleven el pago efectivo real. En general, para la mayoría, las tasas no pasarían del 30\% anual, según lo que declaran los empresarios/as. Pero existen si, casos con una elevada tasa de interés, como la tasa del Banco Azteca de 58\% anual, en un caso, y las tasas que cobran algunos familiares/prestamistas, que oscilan entre 10 y $20 \%$ mensual, para 4 casos, aunque cabe señalar que estos suelen ser prestamos pequeños y de corto plazo, lo que hace más manejable el monto a pagar, lo solicitan (o sufren) empresarios/as que han visto cerrarse el acceso a las IMFs por estar en Infocorp o haber tenido otros problemas.

Los empresarios han solicitado estos préstamos sobre todo para compra de materia prima, en un $61 \%$ de los entrevistados, 17 casos y en menor proporción para pagos de personal, $18 \%$, y compra de pequeńas maquinarias, $11 \%$, conceptos todos estos que podemos agrupar en la noción de capital de trabajo, totalizando un $90 \%$. Solo un $11 \%$ solicita el préstamo para activos fijos, usualmente la construcción de un local, parte de él o maquinaria especializada.

«Tengo máquina computarizada, eso he comprado con el préstamo, me fue fácil conseguirlo, pero el interés es más elevado, lo solicité para maquinaria y una parte materia prima porque confecciono mis propios polos». Luzabel Huari, confeccionista de Huaycán.

Los empresarios/as señalan, en un $89 \%$ de los entrevistados, 25 casos, de que les fue fácil conseguir el crédito, de que no tienen problemas al respecto y de que se consideran clientes. Un $11 \%$ de los entrevistados, 3 casos si señalaron la existencia de problemas; aunque varios los han tenido - en mayor o menor medida - en algún momento de la vida empresarial. La problemática para conseguir los créditos es variada. La de la documentación y requisitos para calificar es la mencionada en la descripción clásica. Si no se cuenta con la documentación sustentadora suficiente sobre el funcionamiento del negocio o de las propiedades, o si no se cuenta con estas, a pesar de tener un negocio, será muy difícil calificar para el crédito.

Obtener el crédito es «dificultoso porque te piden boletas de las compras que uno hace, de los insumos que necesitas para confección; pero yo a veces no cuento con eso porque hago servicios, si yo produjera tendría las boletas». Luzmila Huari, confeccionista de Huaycán.

Un problema con cierto peso, es el hecho de haber incumplido algún pago, lo que lleva a que la persona sea inscrita en Infocorp, con lo cual se convierte en inelegible. Las personas que se encuentran en estos casos han debido hallar otra forma de conseguir financiamiento, lo usual es acudir a familiares y/o prestamistas; en uno o dos casos solicitan créditos a las entidades crediticias vía un tercero. Para las personas que deben conseguir financiamiento fuera del sistema financiero, con familiares y/o prestamistas, la dinámica es otra, pues deben ganar la confianza de estas personas y cumplir sus condiciones, especialmente cuando requieren montos altos. 
«No es tan fácil conseguirlo, hay personas que te prestan pero con los intereses altísimos pero qué le vamos a hacer, para trabajar esta producción hay que prestarse no más», Arthuro Rosales, confeccionista de Huaycán.

Pero el problema central no es obtener el crédito, es pagarlo. El 89\%, 25 de los casos, señalan que están pagando su crédito y la mayoría de ellos señalan que no han tenido dificultades para el pago; relacionan esa ausencia de dificultades con las buenas ventas que están teniendo, sus pedidos y la producción marchan bien.

Un 36\% señalan que han tenido problemas en el transcurso del proceso, aunque tratan de cumplir con el pago. Un 11\%, 3 casos, señalan de que no están pagando. Aunque en ocasiones la falta de pago no necesariamente expresa incumplimiento ya que han optado por esquemas de pagar al final del proceso productivo que están realizando, ello es más factible de hacer cuando se ha conseguido el crédito de prestamistas o familiares, que aceptan ese tipo de esquema, los bancos o instituciones financieras suelen plantear pagos mensuales iniciándolos al mes de otorgado el crédito; los empresarios señalan que los bancos son inflexibles en ese punto.

En los empresarios que señalan que tienen o han tenido dificultades para hacer los pagos, los problemas para pagar surgen sobre todo de problemas de mercado, cuando los empresarios no pueden concretar la venta de sus productos o estos se venden a menores precios. El 70\% de los empresarios en problemas para afrontar los pagos están en ese caso. Pero los problemas también pueden deberse a otro tipo de problemas, un $20 \%$ los ha tenido por retrasos en los pagos de sus clientes, recordemos que ellos suelen trabajar a pedido y sus ingresos suelen depender de un muy reducido número de clientes y si uno falla afecta de manera significativa estos ingresos.

«Hace un par de meses que no estoy pagando he tenido un problema económico, caí en un fracaso hasta recuperarme y también tengo deudas que me hice, estoy pagando y no puedo cumplir con el banco. Los ingresos no son los suficientes para cubrir las cuotas (perdió un cliente) que eran regulares. Los servicios no vienen tanto hasta aca la parte alta (de Huaycán), los del Parque Industrial (en la parte baja) son los que se benefician más de los pedidos», Jack Lazo, confeccionista de Huaycán.
El nivel de los problemas sin embargo es variable, los mencionados tienen que ver sobre todo con problemas de producción, ventas y/o gestión, que retrasan los pagos pero no los afectan. Pero existen problemas que pueden llevar a afectar la continuidad empresarial o a afectarla seriamente. Podríamos hablar de fragilidad frente al crédito, o de fragilidad frente a los schocks externos que obligan a incumplir las condiciones del crédito y que terminan afectando al negocio y/o a la actitud del empresario frente al crédito de las IMFs como un medio para el desarrollo.

«Si he tenido dificultades, cuotas atrasadas por temporada baja, la temporada baja te disminuye el precio y uno tiene que almacenar el material, he tenido problemas con el banco, el refinanciamiento te sube (el coste). Me choco bastante, tuve que hacer recorte de personal, ha cerrado la carpintería temporalmente. Darwin Bautista, carpintero de Huaycán.

«Paso un caso que nos atrasamos un poco y como nosotros nos gustaba poco ellos nos dijeron podemos refinanciar pero nos ensartamos porque era más largo y más caro. Eso fue motivo para dejar de trabajar con el banco, pagaba intereses mas no el capital, tuve que reducir personal. Fue beneficioso, pero en el camino siempre suceden cosas» David Rojas, carpintero.

Aun así el 96\% de los empresarios/as señalan que el crédito les ha sido beneficioso, sobre todo para seguir produciendo; aunque alguno señala que no le es rentable. Algunos empresarios suelen decir que trabajan para el banco. Los empresarios piensan que sería deseable contar con un crédito con menor tasa y un mayor plazo o un periodo de gracia, de al menos un mes, «eso de empezar a pagar desde el primer mes es un problema, pero el Banco no se fija en eso" (Darwin Bautista). Pero señalan también el tema de las condiciones no son lo central «ese no es el problema, es tener trabajo en la cantidad/escala suficiente» (Arthuro Rosales) para poder seguir produciendo. El microcrédito ha sido en conclusión un factor sumamente importante en el desarrollo de las microempresas de Huaycán en tanto les ha permitido financiar su producción, potenciando su desarrollo. 


\section{La importancia del microcrédito para combatir la exclusión}

Las microempresas, usualmente denominadas Mypes y consideradas parte de la economía informal (Rentería 2015), suelen ser pequeñas unidades económicas, surgidas como alternativas frente a la falta de empleo, con escasos niveles de capital, físico y financiero, dirigidas a un mercado local, ofreciendo sus productos o servicios tanto a consumidores finales como a otras empresas de mayor tamańo, con bajos márgenes de rentabilidad y que usualmente operan con importantes niveles de informalidad laboral, administrativa $y$ tributaria. Suelen ubicarse en los sectores de comercio o servicios y caracterizarse por bajos niveles de productividad, uso de tecnologías básicas asociadas a bajos niveles de educación. Suelen operar al margen del marco institucional, sin permiso y sin protección legal de los trabajadores con un difícil acceso a mercados competitivos. (Sulmont 1996; Tokman 1996)

Su principal virtud - desde un punto de vista económico y social - es la cantidad de empleo que generan, sin embargo es un empleo precario, con ingresos sumamente bajos; en este sector no hay garantía de seguridad social de salud y jubilación, ni de vacaciones, ni de gratificaciones ni de todo aquello que significa un empleo de calidad; estamos lejos de la definición de empleo decente que utiliza la OIT. Algunos autores cuestionan incluso el que calificar a estos trabajos $\mathrm{u}$ ocupaciones como empleo, ya que este concepto se asocia más a la existencia de puestos de trabajo definidos con relaciones de subordinación. (rpeij 2006)

Ciertamente, como país, requerimos fortalecer el desarrollo de las microempresas, que brindan puestos de trabajo al $60 \%$ de la PEA y aportan con un $19 \%$ del PBI (INEI 2016). Pero para ello hay que afrontar los problemas centrales que dificultan su desarrollo: la baja productividad, la calidad del empleo, su vinculación a los mercados y eslabonamiento con otros niveles empresariales, acceso al financiamiento e integración a un proceso de desarrollo integral.

Dada su problemática podemos calificar a estas microempresas y sus integrantes como una población con problemas de exclusión. Entendiendo la exclusión como un proceso multidimensional en el que se distinguen tres dimensiones interdependientes; económica, política y cultural, que pueden actuar como barreras para superar la pobreza. La exclusión económica se genera cuando las personas son excluidas del acceso a los activos o a los mercados básicos o son relegadas a segmentos que son menos rentables o más riesgosos, siendo claves el acceso a los mercados de trabajo y crédito (Figueroa 1996).

El acceso al financiamiento, es percibido por la mayoría de los microempresarios, como uno de los problemas fundamentales para su desarrollo. Y ello obedece a la necesidad de los empresarios de cubrir los desembolsos necesarios para elaborar un producto o prestar un servicio; esa necesidad está siempre presente si bien la magnitud de la misma puede variar en función de la modalidad de venta del producto o servicio y/o de la disponibilidad de fondos propios del empresario. El microcrédito sería una opción para brindar acceso - a un determinado sector de la población- al mercado de créditos y la posibilidad de acumular activos económicos.

El microcrédito como política o instrumento para salir de la pobreza se ha desarrollado desde hace varias décadas, ha logrado una especial visibilidad a partir de la experiencia del Banco Grameen (1976) en Bangladesh impulsado por Muhummad Yunus quien recibió el Premio Nobel de la Paz en 2006 (Bornstein 2007). Diversas instituciones internacionales han apostado al microcrédito como un medio de lucha contra la pobreza. En febrero de 1997 se realizó la I Cumbre del Microcrédito en Washington DC., en la que se reunieron más de 2,900 delegados de 137 países. Allí, se lanzó una Campaña de 9 años para alcanzar a 100 millones de las familias más pobres del mundo, especialmente a las mujeres, con crédito para autoempleo y otros servicios financieros para fines del 2005. La ONU declaro el 2005 como el Año de las microfinanzas. En noviembre de 2006, 2,000 delegados de más de 100 países se reunieron en Halifax, Canadá, en la II Cumbre Global de Microcrédito para evaluar el avance logrado.

Diversos estudios muestras que el microcredito logra incrementar el ingreso familiar, e incluso el ahorro familiar. Pues si los pobres tienen acceso a servicios financieros pueden obtener fondos para invertir en activos que fomenten la productividad. $\mathrm{Al}$ acumular activos financieros y tener un seguro los hogares pueden reducir el impacto de desastres. Ello es válido no solo para los pobres sino para cientos de familias que sobreviven con su trabajo y que no tienen acceso a los sistemas financieros (García 2010). 
Aunque la mayor virtud de las microfinanzas es la de ayudar a la gente a mantenerse en el mercado y acceder al sistema financiero. Las microfinanzas, bien encaminadas, conducen a reducir la incidencia de la pobreza. En el ámbito (micro) empresarial, permiten el incremento y/o mayor regularidad de los ingresos y del flujo de caja, mantener la actividad económica y fortalecer los (auto) empleos existentes, incrementos en el capital fijo e incluso cambios tecnológicos en prestatarios con préstamos múltiples. Tiene un papel importante en la supervivencia de las empresas e incluso impactos positivos, aunque pequeños, en el empleo o cantidad de horas trabajadas. En el ámbito familiar permiten incrementar el consumo.

Ciertamente el impulsar el microcrédito es todo un desafío pues las personas, las microempresas enfrentan restricciones para acceder al crédito formal: títulos, garantías, desinformación y desconocimiento sobre cómo operan los intermediarios financieros. Desde el lado de las instituciones microfinancieras deben manejar adecuadamente el riesgo y hacer frente a las necesidades de capital. Y desde el Estado debe reflexionarse sobre la posibilidad de lograr objetivos económicos y sociales a la vez de cautelar los fondos de los depositantes, relacionándose con instituciones privadas que no necesariamente están alineadas con las políticas de gobierno (Trivelli 2000).

Cabe señalar que el microcrédito solo es una opción para los pobres o personas con cierta capacidad de emprendimiento. Mucha gente — de diversos niveles económicos - no puede hacer uso del crédito porque no están en condiciones de emprender una actividad económica.

\section{La evolución del microcrédito en el Perú y sus desafíos}

El Perú es actualmente reconocido como uno de los países con mayor desarrollo del microcrédito, entendiendo este - en términos generales - como la provisión de pequeñas cantidades de dinero a personas tradicionalmente desvinculadas de los servicios bancarios y financieros (EIU 2015). Los primeros programas de microcrédito se iniciaron a fines de los años 80 impulsados por ONG y la cooperación internacional, luego de identificar la existencia de una amplia economía informal que se desarrollaba a la par de los procesos de migración y urbanización.
Programas que se fueron fortaleciendo posteriormente con el ingreso de la Cajas Municipales, el surgimiento de programas estatales y el aliento al surgimiento de entidades especializadas en la provisión de servicios financieros a los sectores más necesitados, como las Edpymes y MiBanco. En los últimos años el ingreso del sector privado, a través de bancos y financieras, ha sido clave para la expansión de este sector y la multiplicación de microcréditos y beneficiarios (Webb 2009).

Hoy en día existen en Perú cerca de 100 instituciones micro financieras (IMF) que proveen de fondos a cerca de 2 millones de personas con préstamos promedio de 1,000 a 10,000 soles por año. El hecho de poner fondos a disposición de las personas permite usualmente fortificar pequeños negocios y se supone contribuye a incrementar los niveles de ingresos y superar situaciones de pobreza.

En los últimos años, y de manera sostenida en los últimos veinte años, desde el Estado y diversos sectores de la sociedad civil se han desarrollado múltiples esfuerzos por promocionar este sector. De hecho en ese lapso, se han diseñado e impulsado diversas políticas de promoción económica, tales como programas de empleo temporal, capacitación laboral para sectores desfavorecidos o servicios de desarrollo empresarial para las MYPE. Son variados los proyectos y programas ejecutados desde el Estado, la cooperación internacional, las ONG y otros sectores de la sociedad civil con el objeto de lograr la inclusión económica.

A no dudarlo, el Estado - a través de sucesivos gobiernos- ha sido un actor principal en el desarrollo de estas iniciativas. Actualmente, son diversos los organismos del Estado con proyectos o responsabilidades en la promoción de la microempresa, principalmente Produce, Cofide, Fogapi. Foncodes, el Ministerio de Trabajo y el Midis han desarrollado también diversos programas en su momento. El reciente paquete legislativo, de enero 2016, acaba de lanzar un nuevo régimen tributario para las MYPE.

Sin embargo, no existe necesariamente una política explicita — si es que podemos asignarle ese nombrepara la promoción de las Mypes o el microcrédito ya que la acción del Estado y de los actores sociales en la promoción económica es dispersa y atomizada, cambiante con las gestiones gubernamentales y no priorizada en la asignación de fondos, además de subordinada al manejo macroeconómico del país y a la concepción de que el mercado es el gran asignador. 
Como política ciertamente estaría todavía en proceso de diseño, legitimación y articulación, y tiene el reto de pasar de la teoría y los programas piloto a una política social con impactos en la mejora de la calidad de vida y la equidad, requiriendo además consensos sobre sus estrategias principales y trascender las iniciativas que se lanzan de gobierno en gobierno (Vildoso 2000)

Se ha mantenido sin embargo, a lo largo de los diversos gobiernos - y de manera subordinada a la lucha contra la pobreza - el criterio de que es necesario impulsar acciones de promoción económica, que suelen estar — a nivel del Estado- bajo responsabilidad de los Ministerios ligados al empleo, la producción y el comercio, aunque son múltiples las instancias que implementan programas de este tipo.

Las principales ventajas de una política social dirigida a promocionar el desarrollo de la micro y pequeña empresa, estribarían en su potencialidad para sentar las bases para salir de la pobreza, a diferencia de los programas asistenciales de lucha contra la pobreza que compensan temporalmente situaciones de carencia. Una política dirigida a desarrollar las capacidades específicas de las personas para que autogeneren su puesto de trabajo, sienta las bases para que cuenten con fuentes propias de ingresos.

Los beneficiarios de tales políticas suelen ser los conductores de las unidades económicas de pequeña escala, especialmente aquellos que, a pesar de conducir microempresas de subsistencia, tienen posibilidades de acceder a mercados más dinámicos. Es decir, empresarios de los sectores populares con posibilidad de desarrollar sus capacidades y no necesariamente miembros de los estratos más pobres, donde tradicionalmente se han focalizado las políticas sociales.

Requerimos pues políticas que pongan el acento en la creación de empleo en los diferentes sectores, a través de políticas y esfuerzos concertados entre los actores económicos y el Estado, como forma de generar a las personas ingresos sostenibles. Políticas que deben dirigirse tanto a los trabajadores formales como informales, poniendo el acento en sectores que generen empleo y asistiendo y apoyando a los trabajadores por cuenta propia.

El actual gobierno ha planteado —vía los decretos legislativos de diciembre 2016 - reducir la informalidad al $40 \%$ fundamentalmente a través de un nuevo régimen tributario para la microempresa, la reducción de multas y deudas y el esbozo de medidas como reducción del IGV en un punto, el diferimiento del pago del IGV, y la prórroga del sistema de compras estatales. Se han dispuesto también normas tendientes a propiciar el desarrollo del factoring y a fortalecer el fondo de garantías para el microcrédito.

Requerimos también políticas y procesos que permitan llevar el crédito, los seguros y los servicios bancarios a sectores más amplios de la población, como una forma de soporte a sus actividades económicas, proporcionándoles capital de trabajo y acceso a servicios financieros, sea a las personas, sus (micro) empresas o los colectivos.

$\mathrm{El}$ acceso a instrumentos financieros puede tener una influencia notable en la reducción del riesgo de caer en situación de pobreza por ingresos. Por ejemplo, el acceso al crédito, o la capacidad de endeudamiento, se asoció con una disminución de la probabilidad de caer en situación de pobreza por ingresos de 3,6 puntos porcentuales en el caso de Chile y de 5,3 puntos porcentuales en el caso de México, en tanto que la posesión de ahorros se asoció con una reducción de 2,7 puntos porcentuales en el caso de Chile. Además, la propiedad de activos durables en el hogar se asoció con una disminución de dicha probabilidad de alrededor de 6 puntos porcentuales en el caso de Perú (PNUD 2016: 73)

El bajo nivel de acceso al crédito y las restricciones de financiamiento son particularmente importantes para los trabajadores informales que requieren mecanismos que les permitan prefinanciar sus actividades o iniciativas.

La falta de acceso al crédito y las restricciones para acceder a financiamiento parecen guardar una estrecha relación con la elevada informalidad y la baja productividad de las empresas de la región. En América Latina hay más de 50 millones de establecimientos productivos pequeños y medianos, de los cuales cerca de 37 millones son informales. De estos, el 40\% declara que necesita un crédito y no tiene acceso, en tanto que un $9 \%$, si bien es sujeto de alguna línea crediticia, encuentra restricciones para acceder a financiamiento (PNUD 2016; 139)

El gran desafío de la política pública en general y de la política social en particular es el de generar procesos de inclusión que permitan a las personas participar plenamente de los procesos económicos, sociales y culturales. Dice un dicho muy común, «no se trata de regalar pescado sino de enseñar a pescar»; pero 
se trata en realidad de entregar a las personas medios y capacidades para que participen de los procesos.

La inclusión económica es parte de este desafíos, se trata de posibilitar el acceso al mercado de trabajo, al mercado de (micro) crédito y a los mercados en general para el conjunto de la población, debiendo prestar una especial atención a los sectores que conocemos comúnmente como sector informal o economía informal, y que reúne a microempresarios, trabajadores asalariados de la economía informal y trabajadores independientes o autónomos.

\section{Referencias bibliográficas}

Bornstein, David (2007). El precio de un sueño: La aventura de Muhammad Yunus y el Grameen Bank. Barcelona: Random House Mondadori. Serie Debate.

EIU. The Economist Intelligence Unit. (2015). Microscopio global 2015. Análisis del entorno para la inclusión financiera. Nueva York: FOMIN, CAF, Acción, Fundación MetLife. EIU.

Figueroa, Adolfo; Sulmont, Denis y Altamirano, Teófilo (1996). Exclusión social y desigualdad en el Perú. Lima: OIT (Instituto Internacional de Estudios Laborales).

García Norberto E. (2010). Reformas, crecimiento e Informalidad. Lima: PUCP - CIES - IEP.

Palomares Palomares, Carlos Iván (2009). Ejes del plan de desarrollo económico local del distrito de Ate. Lima: Edaprospo.

PNUD, Programa de las Naciones Unidas para el Desarrollo (2016). Informe Regional sobre Desarrollo Humano para América Latina y el Caribe. Progreso multidimensional: bienestar más allá del ingreso. IDH2016 multidimensional. Nueva York: PNUD.

Rentería, José María (2015). Brechas de ingresos laborales en el Perú urbano: una exploración de la economía informal. Documento de Trabajo No. 408. Lima: Departamento de Economía PUCP. .

Sulmont, Denis (1996). Iniciativas económicas populares, pequeñas empresas y desarrollo en América Latina: aclaraciones conceptuales y notas para el debate. En Abelardo Vildoso (editor), Microempresa y sectores populares en América Latina: 29-91. Lima: Taller Permanente sobre la Microempresa.

Tokman, Víctor (1996). Fomento productivo de las microempresas urbanas. En Abelardo Vildoso (editor), Microempresa y sectores populares en América Latina: 105129. Lima: Taller Permanente sobre la Microempresa.

Trivelli, Carolina (2000). Provisión de bienes públicos y financiamiento. En Carolina Trivelli y otros, Desafíos del desarrollo rural en el Perú: 75-110. Lima: Diagnóstico y Propuesta 2, Consorcio de Investigación económico y social (CIES).

Vildoso Chirinos, Abelardo (2000). La configuración de una política social de apoyo a la microempresa: realidad y límites. En Felipe Portocarrero, Políticas sociales en el Perú: Nuevos aportes: 321-348. Lima: Red para el desarrollo de las ciencias sociales en el Perú.

Webb, Richard; Lucy Conger; Patricia Inga (2009). El àrbol de mostaza. Historia de las microfinanzas en el Perú. Lima: Universidad de San Martín de Porres.

Ypeij, Annelou (2006). Produciendo contra la pobreza: la microempresa vista desde el género. Lima: IEP. 